\title{
Synthesis, characterization and magnetostructural correlation studies on three binuclear copper complexes of pyrimidine derived Schiff base ligands
}

\author{
Samik Gupta ${ }^{a}$, Sachindranath Pal ${ }^{\mathrm{b}}$, Anil Kumar Barik ${ }^{\mathrm{c}}$, Arijit Hazra ${ }^{\mathrm{a}}$, Somnath Roy ${ }^{\mathrm{a}}$, Tarak Nath Mandal ${ }^{\mathrm{a}}$, \\ Shie-Ming Peng ${ }^{\mathrm{d}}$, Gene-Hsiang Lee ${ }^{\mathrm{d}}$, M. Salah El Fallah ${ }^{\mathrm{e}, *}$, Javier Tercero ${ }^{\mathrm{e}}$, Susanta Kumar Kar ${ }^{\mathrm{a}, *}$ \\ ${ }^{a}$ Department of Chemistry, University College of Science, University of Calcutta, 92 A.P.C. Road, Kolkata 700 009, West Bengal, India \\ ${ }^{\mathrm{b}}$ Department of Chemistry, Sree Chaitanya College, Habra, North 24 Parganas, West Bengal, India

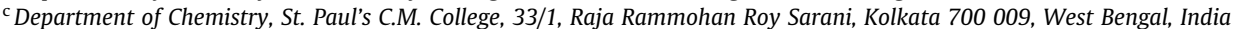 \\ ${ }^{\mathrm{d}}$ Department of Chemistry, National Taiwan University, Taipei 106, Taiwan, ROC \\ e Departament de Química Inorgànica, Facultat de Química, Universitat de Barcelona, Martí Franquès 1-11, 08028 Barcelona, Spain
}

\section{A R T I C L E I N F O}

\section{Article history:}

Received 5 February 2008

Accepted 6 May 2008

Available online 21 June 2008

\section{Keywords:}

Binuclear copper(II) complex

Ferromagnetic

Antiferromagnetic

Pyrimidine derived Schiff base ligands

Magnetostructural correlation

\begin{abstract}
A B S T R A C T
Three binuclear $\mathrm{Cu}(\mathrm{II})$ complexes of two pyrimidine derived Schiff base ligands, 2-S-methyl-6-methyl-4formyl pyrimidine- $N(4)$-ethyl thiosemicarbazone $\left(\mathrm{HL}_{1}\right)$ and salicyl hydrazone of 2-hydrazino-4,6-dimethylpyrimidine $\left(\mathrm{HL}_{2}\right)$, have been prepared. $\mathrm{HL}_{1}$ produces a bis( $\mu$-thiolato) $\mathrm{Cu}(\mathrm{II})$ complex co-crystallizing with its mononuclear analog, $\left[\mathrm{Cu}_{2}\left(\mathrm{~L}_{1}\right)_{2}\left(\mathrm{NO}_{3}\right)_{2}\right]\left[\mathrm{Cu}\left(\mathrm{L}_{1}\right)\left(\mathrm{NO}_{3}\right)\right](\mathbf{1})$. On the other hand $\mathrm{HL}_{2}$ shows versatility by producing two different classes of binuclear $\mathrm{Cu}(\mathrm{II})$ complexes, a bis( $\mu$-phenoxo) complex $\left[\mathrm{Cu}_{2}\left(\mathrm{~L}_{2}\right)_{2}\left(\mathrm{NO}_{3}\right)_{2}\right](2)$ and another a $\left(\mu-4,4^{\prime}\right.$-bipyridyl) complex, $\left[\mathrm{Cu}_{2}\left(\mathrm{~L}_{2}\right)_{2}\left(\mu-4,4^{\prime}\right.\right.$-bipyridyl $\left.)\left(\mathrm{NO}_{3}\right)_{2}\right](3)$ under suitable conditions. All the three complexes show distorted square pyramidal geometry around each $\mathrm{Cu}$ atom but to a varied extent. Magnetic behavior of complex 1 shows that it is strongly ferromagnetic in nature whereas compounds $\mathbf{2}$ and $\mathbf{3}$ are weakly antiferromagnetic in nature. A magnetostructural correlation study combined with molecular modelling on complexes $\mathbf{1}$ and $\mathbf{2}$ has thrown light on the difference on magnetic interaction between the $\mathrm{Cu}$ atoms in these two complexes. Various factors that may be responsible for such differences are also explored. A novel and potentially useful $\mathrm{pH}$ dependant conversion of $\mathbf{3}$ to $\mathbf{2}$ has also been noticed.
\end{abstract}

(c) 2008 Elsevier Ltd. All rights reserved.

\section{Introduction}

The chemistry of dinuclear copper complexes with ligands of biological relevance and with metal centers at close proximity is one of the central themes of current research [1-3] due to their interesting structural, electrochemical and magnetic properties [4] and also because of their relevance to the active sites of several metalloenzymes [5] as synthetic models [6,7]. Apart from the binuclear or polynuclear copper(II) complexes of multidentate donor ligands containing in-built bridging units, synthesis and characterization of di, tri and polynuclear copper complexes using bridging molecules like 4,4'-bipyridyl [8], pyrazine [9] and 1,2 bis(4-pyridyl) ethane [10], etc. are also well documented. These bridging molecules may act singularly or in cooperation with other ligands in the complexes and play a crucial role towards developing diverse innovative structural networks, such as chains, sheets and matrices

\footnotetext{
* Corresponding authors. Tel.: +91 033 24322936; fax: +91 03323519755 (S.K. Kar).

E-mail addresses: salah.elfallah@qi.ub.es ( M. Salah El Fallah),skkar_cu@yahoo. co.in (S.K. Kar)
}

[11]. Such compounds have found potential applications in catalysis [12], absorption chemistry [13] and molecular magnetism [14].

In the present work we report the synthesis and structural characterization of three dinuclear copper (II) complexes using two pyrimidine based Schiff base ligands, $\mathrm{HL}_{1}$ and $\mathrm{HL}_{2}$ (Fig. 1). The former one, 2-S-methyl-6-methyl-4-formylpyrimidine- $N(4)$-ethyl thiosemicarbazone forms a binuclear bis( $\mu$-thiolato) copper(II) complex (1). This complex being pyrimidine derived is a refreshing addition among many other pyridine derived similar complexes [15]. The second chosen ligand $\mathrm{HL}_{2}$, has restricted electron donating capacity because it produces a five membered and a six membered ring at the metal centers (chelation asymmetry) $[16,17]$. Hence the metal ion's urge for electrons may be supplemented intrinsically by forming a transaxial bis( $\mu$-phenoxo) dimer or by bridging separate monomeric units through an externally added bridging ligand such as 4,4'-bipyridyl. In this work both the possibilities have been duly exploited in synthesizing complexes $\mathbf{2}$ and $\mathbf{3}$ respectively. Further, careful selection of the ligands ensures that the synthesized bis( $\mu$-phenoxo) and the bis( $\mu$-thiolato) complexes $\mathbf{1}$ and 2 are similar in structure with subtle variations in co-ordination atmosphere for which they are suitable for attempting a magnetostructural correlation study on them. Temperature dependant magnetic 
<smiles>Cc1cc(C)nc(N/N=C/c2ccccc2O)n1</smiles>

(1)<smiles>CCNC(=S)N/N=C/c1cc(C)nc(C)n1</smiles>

(2)

Fig. 1. Representative diagram of ligand $\mathrm{HL}_{2}(\mathbf{1})$ and ligand $\mathrm{HL}_{1}(\mathbf{2})$.

moment studies and molecular modelling have also led to a comparative account of the variation of their magnetic behavior. The 4,4'-bipyridyl bridged complex 3 has been found to have the weakest metal-metal interaction as the metal centers here are far apart.

\section{Experimental}

\subsection{Materials}

Ethyl diethoxy acetate and N(4)-ethyl-3-thiosemicarbazide, Phosphorus oxychloride, acetyl acetone, urea and hydrazine hydrate were obtained from Aldrich Chemicals, USA and used without further purification. Solvents were also used as received from commercial sources.

\subsection{Syntheses}

\subsubsection{Preparation of ligand $H L_{1}$}

The ligand $\mathrm{HL}_{1}$ was synthesized and characterized using the same procedure as reported earlier [18,19].

\subsubsection{Preparation of ligand $H L_{2}$}

The ligand $\mathrm{HL}_{2}$ was prepared by using 2-hydrazino 4,6-dimethyl pyrimidine and salicylaldehyde in a method similar to that reported by Chiswell and Lions [20]. When a methanolic solution of $1.39 \mathrm{~g}$ (10 mmol) of 2-hydrazino 4,6-dimethyl pyrimidine refluxed with a methanolic solution of $1.21 \mathrm{~g}(10 \mathrm{mmol})$ of salicylaldehyde for $2 \mathrm{~h}$ and the resulting solution kept for slow evaporation, ligand $\mathrm{HL}_{2}$ separated as crystals from the mother liquor. Filtered and dried in vacuo over fused $\mathrm{CaCl}_{2}$. Yield: $2.20 \mathrm{~g}$ (90\%). The compound melted with decomposition at $280{ }^{\circ} \mathrm{C}$. IR $\left(v, \mathrm{~cm}^{-1}\right): 3247(v \mathrm{~N}-\mathrm{H})$, $1620(v \mathrm{C}=\mathrm{C}), 1566(v \mathrm{C}=\mathrm{NH}), 885\left(v \mathrm{C}_{\mathrm{pym}}-\mathrm{H}\right), 1255(v \mathrm{C}-\mathrm{O}) ;{ }^{1} \mathrm{H}$ NMR (300 MHz, $\left.\mathrm{CDCl}_{3}, 25^{\circ} \mathrm{C}, \mathrm{TMS}\right) \delta / \mathrm{ppm}:(6.68)\left(\mathrm{s}, 1 \mathrm{H}, \mathrm{C}_{5}-\mathrm{H}\right.$ pyrimidine), $(6.8-7.3)\left(\mathrm{m}, 4 \mathrm{H},-\mathrm{C}_{6} \mathrm{H}_{4}\right),(8.2)(\mathrm{s}, 1 \mathrm{H},-\mathrm{CH}=\mathrm{N}-)$, (12.8) $(\mathrm{s}, 1 \mathrm{H}$, aromatic-OH), (2.28) $(\mathrm{s}, 1 \mathrm{H}, \mathrm{N}-\mathrm{H}$ of hydrazone), (2.46-2.53) (m, 6H, $\left.\mathrm{CH}_{3}\right)$

2-Hydrazino 4,6-dimethyl pyrimidine was prepared using another literature method $[21,22]$.

\subsubsection{Preparation of the complex $\left[\mathrm{Cu}_{2}\left(\mathrm{~L}_{1}\right)_{2}\left(\mathrm{NO}_{3}\right)_{2}\right]\left[\mathrm{Cu}\left(\mathrm{L}_{1}\right)\left(\mathrm{NO}_{3}\right)\right](\mathbf{1})$}

The complex 1 was prepared by simply adding an ethanolic solution of hydrated cupric nitrate ( $1 \mathrm{mmol}, 295.5 \mathrm{mg}$ ) drop wise to a hot stirred ethanolic solution of ligand $\mathrm{HL}_{1}(0.269 \mathrm{~g}, 1 \mathrm{mmol})$. The resulting greenish-yellow solution was refluxed at water bath temperature for $1 \mathrm{~h}$. The solution was filtered and kept for slow evaporation. The dark green compound that separated was filtered off, washed with ice-cold ethanol and dried over fused $\mathrm{CaCl}_{2}$. Yield
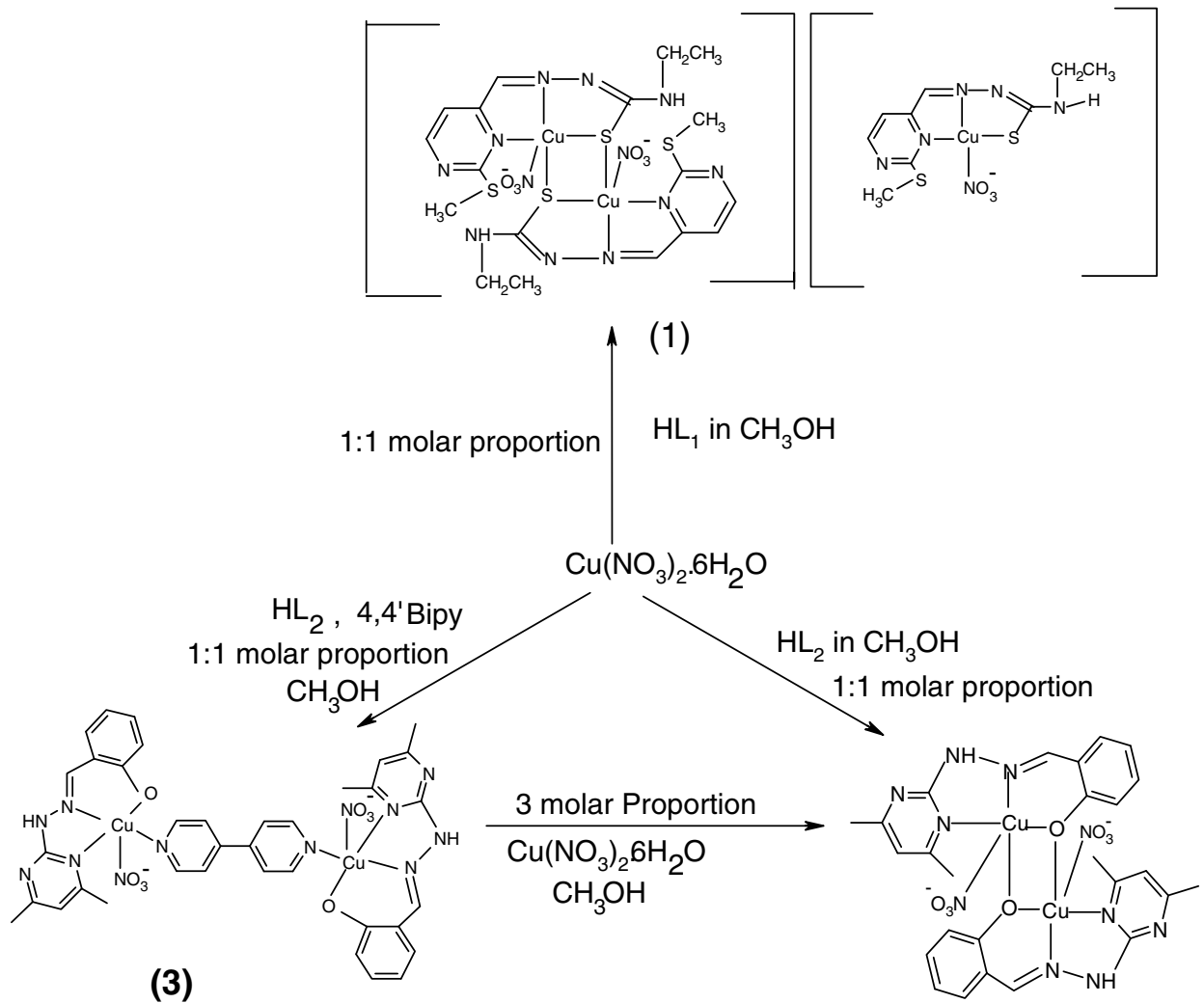

(2)

Fig. 2. A scheme showing the method of preparation for the complexes 1, $\mathbf{2}$ and $\mathbf{3}$. 
55\%. Anal. Calc. for $\mathrm{C}_{30} \mathrm{~S}_{6} \mathrm{~N}_{18} \mathrm{O}_{9} \mathrm{H}_{42} \mathrm{Cu}_{3}$ : C, 30.49; H, 3.18; N, 17.98 . Found: $\mathrm{C}, 30.12 ; \mathrm{H}, 3.56 ; \mathrm{N}, 17.81 \%$. IR $\left(v, \mathrm{~cm}^{-1}\right): 1582 v(\mathrm{C}=\mathrm{N})$, $1601 v(\mathrm{C}=\mathrm{C}), 750 v(\mathrm{C}=\mathrm{S}), 800.6\left(v 2\right.$ of $\left.\mathrm{NO}_{3}\right), 1483,1292(v 3$ of $\left.\mathrm{NO}_{3}\right)$. UV-Vis $(\lambda / \mathrm{nm})\left(\varepsilon / \mathrm{L}^{-1} \mathrm{~mol} \mathrm{~cm}{ }^{-1}\right): 332.5 \quad(30130)\left(\mathrm{n} \rightarrow \pi^{*}\right.$ pyrimidine), $434(10000)$ (CT, pyrimidine $\rightarrow \mathrm{Cu}), 628(440)(\mathrm{d} \rightarrow$ d). $\mathrm{CV}_{\mathrm{pc}} /(\mathrm{V}):-0.23,-0.92\left[\mathrm{Cu}^{\mathrm{II}} \mathrm{Cu}^{\mathrm{II}} \rightarrow \mathrm{Cu}^{\mathrm{II}} \mathrm{Cu}^{\mathrm{I}}, \mathrm{Cu}^{\mathrm{II}} \mathrm{Cu}^{\mathrm{I}} \rightarrow \mathrm{Cu}^{\mathrm{I}} \mathrm{Cu}^{\mathrm{I}}\right]$, $\mathrm{Epa} /(\mathrm{V}):+0.40\left[\mathrm{Cu}^{\mathrm{II}} \mathrm{Cu}^{\mathrm{II}} \rightarrow \mathrm{Cu}^{\text {II }} \mathrm{Cu}^{\mathrm{III}}\right]$.

$\mathrm{X}$-ray quality crystals were grown by slow evaporation of ethanolic solution of the complex at room temperature.

\subsubsection{Preparation of the complex $\left[\mathrm{Cu}_{2}\left(\mathrm{~L}_{2}\right)_{2}\left(4,4^{\prime}\right.\right.$-bipy) $\left.\left(\mathrm{NO}_{3}\right)_{2}\right]$ (3)}

To a mixture of 4,4'-bipyridyl ( $1 \mathrm{mmol}, 150 \mathrm{mg}$ ) and $\mathrm{HL}_{2}$ $(1 \mathrm{mmol}, 241 \mathrm{mg})$ in a methanolic solution $(20 \mathrm{ml})$, of $\mathrm{Cu}\left(\mathrm{NO}_{3}\right)_{2}$. $6 \mathrm{H}_{2} \mathrm{O}$ (1 mmol, $295.5 \mathrm{mg}$ ) in the same solvent was added with constant stirring. Immediately, a dirty green precipitate appeared. Stirring was continued for $15 \mathrm{~min}$. The precipitate was filtered off, washed with methanol and dried over fused $\mathrm{CaCl}_{2}$ (Yield 80\%). Anal. Calc. for $\mathrm{C}_{46} \mathrm{~N}_{14} \mathrm{O}_{8} \mathrm{H}_{40} \mathrm{Cu}_{2}$ : C, 51.92; $\mathrm{H}, 3.76 ; \mathrm{N}, 18.43$. Found: C, 51.43; H, 3.62; N, 18.59\%. IR $v /\left(\mathrm{cm}^{-1}\right): 1561 v(\mathrm{C}=\mathrm{N})$ $1611 v(\mathrm{C}=\mathrm{C}) 814\left(v 2\right.$ of $\left.\mathrm{NO}_{3}\right) 1304,1418\left(v 3\right.$ for $\left.\mathrm{NO}_{3}\right) . \mathrm{UV}-\mathrm{Vis}(\lambda / \mathrm{nm})$ $\left(\varepsilon / \mathrm{L}^{-1} \mathrm{~mol} \mathrm{~cm}{ }^{-1}\right): \quad 332.5 \quad(30130) \quad\left(\mathrm{n} \rightarrow \pi^{*} \quad\right.$ pyrimidine $), 434$ $(10000)(\mathrm{CT}$, pyrimidine $\rightarrow \mathrm{Cu}), 628(440)(\mathrm{d} \rightarrow \mathrm{d}) . \mathrm{CV} E_{\mathrm{pc}} /(\mathrm{V})$ : $-0.42,-0.72\left[\mathrm{Cu}^{\mathrm{II}} \mathrm{Cu}^{\mathrm{II}} \rightarrow \mathrm{Cu}^{\mathrm{II}} \mathrm{Cu}^{\mathrm{I}}, \mathrm{Cu}^{\mathrm{II}} \mathrm{Cu}^{\mathrm{I}} \rightarrow \mathrm{Cu}^{\mathrm{I}} \mathrm{Cu}^{\mathrm{I}}\right], \mathrm{Epa} /(\mathrm{V}):$ $+0.479\left[\mathrm{Cu}^{\mathrm{II}} \mathrm{Cu}^{\mathrm{II}} \rightarrow \mathrm{Cu}^{\mathrm{II}} \mathrm{Cu}^{\mathrm{III}}\right]$.

The compound was found to be sparingly soluble in common organic solvents; hence X-ray quality crystals were obtained from a mixed solvent of DMF and $\mathrm{CH}_{3} \mathrm{OH}$ by slow evaporation.

\subsubsection{Preparation of the complex $\left[\mathrm{Cu}_{2}\left(\mathrm{~L}_{2}\right)_{2}\left(\mathrm{NO}_{3}\right)_{2}\right]$ (2)}

Method $a$ : The complex 2 was prepared by adding an methanolic solution $(10 \mathrm{ml})$ of $\mathrm{Cu}\left(\mathrm{NO}_{3}\right)_{2} \cdot 6 \mathrm{H}_{2} \mathrm{O}(1 \mathrm{mmol}, 295.5 \mathrm{mg})$ to a methanolic solution (15 ml) of ligand $\mathrm{HL}_{2}$, (1 mmol, $242 \mathrm{mg}$ ) under constant stirring condition. Stirring was continued for half an hour, When dark brown micro crystalline compound separated. It was filtered off, washed with methanol and dried over fused $\mathrm{CaCl}_{2}$. Yield (62\%). Anal. Calc. for $\mathrm{C}_{26} \mathrm{~N}_{10} \mathrm{O}_{8} \mathrm{H}_{24} \mathrm{Cu}_{2}$ : C, $41.54 \mathrm{H}, 3.19 ; \mathrm{N}, 18.64$. Found. C, 41.12; H; 3.52; N,18.69\%. IR $v /\left(\mathrm{cm}^{-1}\right): 1546 v(\mathrm{C}=\mathrm{N})$, $1607 v(\mathrm{C}=\mathrm{C}), 807\left(v 2\right.$ of $\left.\mathrm{NO}_{3}\right), 1470,1293\left(v 3\right.$ of $\left.\mathrm{NO}_{3}\right) . \mathrm{UV}-\mathrm{Vis}$ $(\lambda / \mathrm{nm})\left(\varepsilon / \mathrm{L}^{-1} \mathrm{~mol} \mathrm{~cm}^{-1}\right): 332.5(32400)\left(\mathrm{n} \rightarrow \pi^{*}\right.$ pyrimidine $), 383$ $(16000)$ (Phenoxide $\rightarrow \mathrm{Cu}), 429(19200)$ (CT, pyrimidine $\rightarrow \mathrm{Cu}$ ), $675(300)(\mathrm{d} \rightarrow \mathrm{d}) . \mathrm{CV} E_{\mathrm{pc}} /(\mathrm{V}):-0.44,-0.62\left[\mathrm{Cu}^{\mathrm{II}} \mathrm{Cu}^{\mathrm{II}} \rightarrow \mathrm{Cu}^{\mathrm{II}} \mathrm{Cu}^{\mathrm{I}}\right.$, $\left.\mathrm{Cu}^{\mathrm{II}} \mathrm{Cu}^{\mathrm{I}} \rightarrow \mathrm{Cu}^{\mathrm{I}} \mathrm{Cu}^{\mathrm{I}}\right], \mathrm{Epa} /(\mathrm{V}):+0.515\left[\mathrm{Cu}^{\mathrm{II}} \mathrm{Cu}^{\mathrm{II}} \rightarrow \mathrm{Cu}^{\mathrm{II}} \mathrm{Cu}^{\mathrm{III}}\right]$.

$\mathrm{X}$-ray quality crystals were grown by slow evaporation of a methanolic solution of the complex at room temperature.

Method b: To an ethanolic suspension of complex 3 (223 mg, $0.5 \mathrm{mmol}), \mathrm{Cu}(\mathrm{NO} 3)_{2} \cdot 6 \mathrm{H}_{2} \mathrm{O}(1.5 \mathrm{mmol}, 443.2 \mathrm{mg})$ was added and the mixture was refluxed for ca. $2 \mathrm{~h}$ at water bath temperature. A brown colored solution resulted during this time along with a blue violet insoluble residue which could not be characterized. It was filtered and kept for slow evaporation. Dark blue crystals of complex 2 was found to deposit from the solution within few days.

\subsection{Physical measurements}

Elemental analyses (C, $\mathrm{H}$ and N), IR spectra ( $\mathrm{KBr}$ discs, 4000$200 \mathrm{~cm}^{-1}$ ), ${ }^{1} \mathrm{H}$ NMR spectra (DMSO- $d_{6}$ ) and UV-Vis spectra $(\mathrm{MeCN})$, were done with a Perkin-Elmer Model 240 C CHN analyzer, a Jasco FTIR model 420 spectrophotometer, and a Hitachi U-3501 spectrophotometer, respectively. Cyclic voltammetry (CV) experiments were carried out using Sycopel Model 77 AEW2 $1820 \mathrm{~F} / \mathrm{S}$ instrument. The measurements were performed at $300 \mathrm{~K}$ in a DMF solution containing $0.2 \mathrm{M}$ TEAP and $10^{-3}-10^{-4} \mathrm{M}$ $\mathrm{Cu}(\mathrm{II})-\mathrm{Cu}(\mathrm{II})$ complexes 1, 2, 3, deoxygenated by bubbling with nitrogen. A platinum wire, a platinum coil and a SCE were used as a working, a counter and reference electrodes, respectively. Magnetic susceptibility measurements for compounds 1, 2 and 3 were carried out on polycrystalline samples, at the Servei de Magnetoquímica of the Universitat de Barcelona, with a Quantum Design SQUID MPMS-XL susceptometer apparatus working in the range $2-300 \mathrm{~K}$ under magnetic field of approximately $500 \mathrm{G}$ (2$30 \mathrm{~K})$ and $1000 \mathrm{G}(35-300 \mathrm{~K})$. Diamagnetic corrections were estimated from Pascal Tables. The EPR spectra have been recorded on X-band Bruker Spectrometer (ESR 300E), working with an oxford helium liquid cryostat for variable temperature.

\subsection{Crystallographic measurements}

Relevant crystallographic data are listed in Table 1 . Intensity data for $\mathbf{1}$ and $\mathbf{2}$ were measured on a Bruker SMART APEX CCD diffractometer and the same for $\mathbf{3}$ were measured on a NONIUS Kappa-CCD diffractometer, using graphite-monochromated Mo $\mathrm{K} \alpha$ radiation $(\lambda=0.71073 \AA)$ in the $\omega-2 \theta$ scan mode. These were corrected for Lorentz-polarization effects. The structures were solved by using sHELXs-97 package of program and refined by full matrix least-squares technique based on $F^{2}$ (SHELxL-97). Hydrogen atoms were added in the calculated positions. Selected bond angles and bond distances are supplied in Table S1 (Supplementary data). Perspective view of the complexes $\mathbf{1}, \mathbf{2}$ and $\mathbf{3}$ along with the atom numbering schemes are shown in Figs. 3-5.

\section{Results and discussion}

\subsection{Synthesis}

The ligand $\mathrm{HL}_{1}$, used in this work, is prepared using standard literature procedures $[18,19]$. Ligand $\mathrm{HL}_{1}$ has been employed to synthesize the bis( $\mu$-thiolato) complex, $\mathbf{1}$, while the ligand $\mathrm{HL}_{2}$ is synthesized for the first time for preparation of the bis( $\mu$-phenoxo) complex, 2.

With the examples of several other closely related ligand systems to both $\mathrm{HL}_{1}$ and $\mathrm{HL}_{2}$ reported earlier as binucleating ligands towards $\mathrm{Cu}^{2+}$ ion [23], it seemed worth while to try them out for this purpose and establish a comparative relation between the resulting thiolato and phenoxide bridged complexes with respect to their structures and magnetic behavior. Our pursuit turned fruitful when binuclear copper complexes resulted from both the ligands using $\mathrm{Cu}\left(\mathrm{NO}_{3}\right)_{2}, 6 \mathrm{H}_{2} \mathrm{O}$ as the precursor. Both ligands act as tridentate mono negative type donors towards $\mathrm{Cu}^{2+}$ ion and the complexes obtained were notably similar from the structural point of view barring the bridging donor atoms. Further we extended the purview of this work by attempting the synthesis of $4.4^{\prime}$-bipyridyl and pyrazine bridged dinuclear $\mathrm{Cu}^{2+}$ complexes with ligand $\mathrm{HL}_{2}$. While the 4,4'-bipyridyl bridged complex was easily formed, the attempt with pyrazine was unsuccessful. This is because formation of such a complex would require a close approach of the monomeric bulky units and would exert a severe steric congestion around the bridging pyrazine ring making the species highly unstable. Thus at such a close approach of the monomeric units formation of the phenoxide bridge was favored to a pyrazine bridged binuclear complex.

A most intriguing observation was that the bipyridyl bridged complex, 3, which is stable in heat (refluxing $\mathrm{MeOH}$ temperature), gets transformed to complex $\mathbf{2}$ when a suspension of $\mathbf{3}$ in $\mathrm{MeOH}$ is refluxed with 3 equiv. of $\mathrm{Cu}\left(\mathrm{NO}_{3}\right)_{2} \cdot 6 \mathrm{H}_{2} \mathrm{O}$. Within a span of $2 \mathrm{~h}$, complex 3 which was originally insoluble in $\mathrm{MeOH}$ became completely soluble to give a brown solution. Slow evaporation of this solution resulted in X-ray quality crystals of $\mathbf{2}$. This conversion of $\mathbf{3}$ to $\mathbf{2}$ may be attributed to the slight decrease of $\mathrm{pH}$ in the resulting solution on addition of excess $\mathrm{Cu}\left(\mathrm{NO}_{3}\right)_{2} \cdot 6 \mathrm{H}_{2} \mathrm{O}$ to the suspension of 3 in $\mathrm{MeOH}$. Solvolysis of the metal salt causes lowering of $\mathrm{pH}(4.5-5.0)$ which is just enough to free the co-ordinated 
Table 1

Crystal data and structure refinement for complex 1, 2, 3

\begin{tabular}{|c|c|c|c|}
\hline Crystal & Complex 1 & Complex 2 & Complex3 \\
\hline Empirical formula & $\mathrm{C}_{20} \mathrm{H}_{28} \mathrm{Cu}_{2} \mathrm{~N}_{12} \mathrm{O}_{6} \mathrm{~S}_{4}$ & $\mathrm{C}_{26} \mathrm{H}_{26} \mathrm{Cu}_{2} \mathrm{~N}_{10} \mathrm{O}_{8}$ & $\mathrm{C}_{36} \mathrm{H}_{34} \mathrm{Cu}_{2} \mathrm{~N}_{12} \mathrm{O}_{8}$ \\
\hline Formula weight & 787.86 & 731.65 & 889.84 \\
\hline Temperature (K) & 295(2) & $295(2)$ & $150(2)$ \\
\hline Crystal system & monoclinic & monoclinic & triclinic \\
\hline Space group & $P 2(1) / n$ & $P 2(1) / c$ & $P \overline{1}$ \\
\hline \multicolumn{4}{|l|}{ Unit cell dimensions } \\
\hline$a(\AA)$ & $14.6940(7)$ & $7.5729(3)$ & $7.4141(4)$ \\
\hline$b(\AA)$ & $14.0601(7)$ & $13.1332(6)$ & $9.9865(6)$ \\
\hline$c(\AA)$ & $15.8096(8)$ & $14.8400(7)$ & $12.8196(7)$ \\
\hline$\alpha\left(^{\circ}\right)$ & 90 & 90 & $105.026(1)$ \\
\hline$\beta\left(^{\circ}\right)$ & $111.190(1)$ & $96.7425(18)$ & $99.735(1)$ \\
\hline$\gamma\left({ }^{\circ}\right)$ & 90 & 90 & $95.096(1)$ \\
\hline Volume $\left(\AA^{3}\right)$ & $3045.4(3)$ & $1465.73(11)$ & $894.70(9)$ \\
\hline$Z$ & 4 & 1 & 2 \\
\hline Absorption coefficient $\left(\mathrm{mm}^{-1}\right)$ & 1.729 & 1.519 & 1.262 \\
\hline$F(000)$ & 1608 & 748 & 456 \\
\hline Crystal size (mm) & $0.35 \times 0.20 \times 0.20$ & $0.50 \times 0.20 \times 0.10$ & $0.30 \times 0.13 \times 0.05$ \\
\hline$\theta$ Range for data collection $\left({ }^{\circ}\right)$ & $2.00-27.50$ & $2.76-27.50$ & $2.32-27.50$ \\
\hline Reflections collected & 24467 & 11639 & 11697 \\
\hline Independent reflections $\left(R_{\text {int }}\right)$ & $7004(0.0340)$ & $3347(0.0585)$ & $4108(0.0418)$ \\
\hline Completeness to $\theta=27.50^{\circ}(\%)$ & 100.0 & 99.8 & 99.9 \\
\hline Absorption correction & semi-empirical from equivalents & none & semi-empirical from equivalents \\
\hline Maximum and minimum transmission & 0.7236 and 0.5828 & 0.782 and 0.536 & 0.9396 and 0.7033 \\
\hline Refinement method & full-matrix least-squares on $F^{2}$ & full-matrix least-squares on $F^{2}$ & full-matrix least-squares on $F^{2}$ \\
\hline Data/restraints/parameters & $7004 / 0 / 397$ & $3347 / 0 / 210$ & $4108 / 0 / 264$ \\
\hline Goodness-of-fit on $F^{2}$ & 1.015 & 1.075 & 1.008 \\
\hline Final $R$ indices $[I>2 \sigma(I)]$ & $R_{1}=0.0394, w R_{2}=0.0948$ & $R_{1}=0.0459, w R_{2}=0.1314$ & $R_{1}=0.0550, w R_{2}=0.1315$ \\
\hline$R$ indices (all data) & $R_{1}=0.0552, w R_{2}=0.1026$ & $R_{1}=0.0661, w R_{2}=0.1395$ & $R_{1}=0.0652, w R_{2}=0.1384$ \\
\hline Largest difference in peak and hole $\left(\mathrm{e} \AA^{-3}\right)$ & 0.440 and -0.299 & 0.804 and -0.404 & 1.570 and -0.489 \\
\hline
\end{tabular}

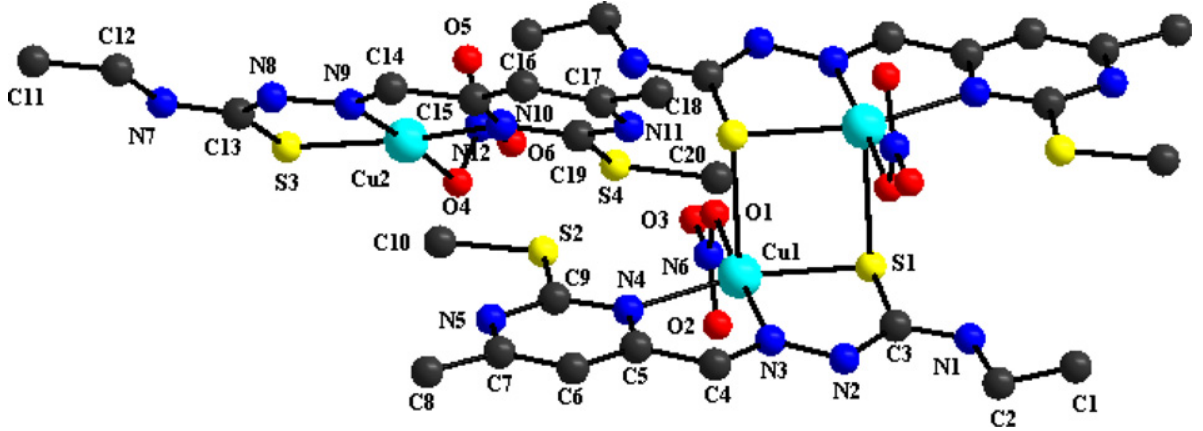

Fig. 3. Structural representation of complex $\mathbf{1}$.



Fig. 4. Structural representation of complex 2 .

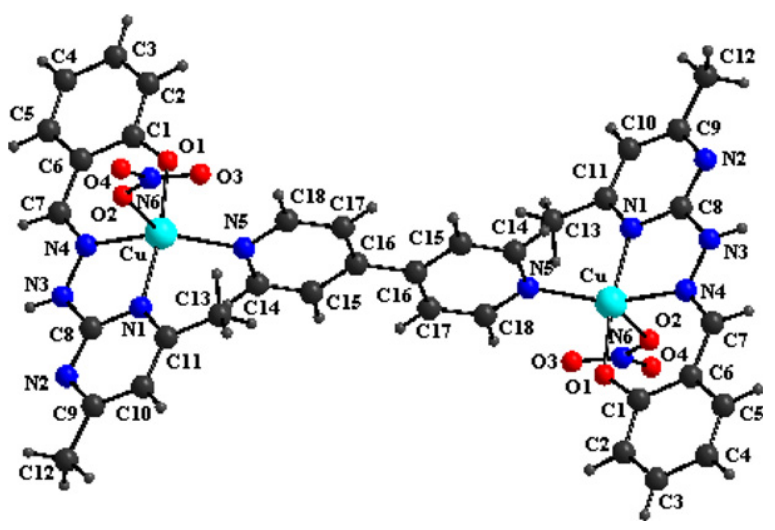

Fig. 5. Structural representation of complex 3. 
4,4'-bipyridyl with a view to protonate it. This slight decrease of $\mathrm{pH}$ is however insufficient to protonate other donor atom/ion in the deprotonated prime ligand and thus no change is brought about in the main ligand's binding property. Complex 3 can thus easily get transformed to $\mathbf{2}$ using the bridging capability of phenoxide ion. The reaction scheme for the preparation of the complexes is shown in Fig. 2.

\subsection{Spectroscopic characterization}

The ligand $\mathrm{HL}_{1}$ shows characteristic IR bands for $v(\mathrm{C}=\mathrm{N})$ at $1608 \mathrm{~cm}^{-1}$. This is shifted ca. $26 \mathrm{~cm}^{-1}$ towards lower energy in the complex 1 indicating co-ordination via azomethine nitrogen [24]. The ligand $\mathrm{HL}_{1}$ shows a band at $800 \mathrm{~cm}^{-1}$ assigned to $v(\mathrm{C}=\mathrm{S})$, this is also shifted towards the lower frequency to ca. $750 \mathrm{~cm}^{-1}$ confirming co-ordination via thiolate sulphur atom in the complex 1. A band at $272 \mathrm{~cm}^{-1}$ may be assigned to $v\left(\mathrm{Cu}-\mathrm{O}_{\mathrm{NO}_{3}}\right)$ consistent with bands at $253-280 \mathrm{~cm}^{-1}$ for other nitrato complexes [25]. Moreover two strong bands at $1420 \mathrm{~cm}^{-1}$ and $1306 \mathrm{~cm}^{-1}$ at a separation of $114 \mathrm{~cm}^{-1}$ indicate that the nitrate is bound in monodentate fashion [26].

In the ligand $\mathrm{HL}_{2}$ the significant bands are observed at $1566 \mathrm{~cm}^{-1}$ for $v(\mathrm{C}=\mathrm{N}), 1620 \mathrm{~cm}^{-1}$ for $v(\mathrm{C}=\mathrm{C}), 2924 \mathrm{~cm}^{-1}$ for $v(\mathrm{O}-\mathrm{H})$ and $v(\mathrm{~N}-\mathrm{H})$ at $3247 \mathrm{~cm}^{-1}$. Among these the broad band at $2924 \mathrm{~cm}^{-1}$ is absent in the complexes 2 and 3 showing that the phenolic $-\mathrm{OH}$ is deprotonated in the complexes.

Interestingly, the $v(\mathrm{C}=\mathrm{N})$ band undergoes more deviation towards the lower energy in complex $2\left(1546 \mathrm{~cm}^{-1}\right)$ compared to 3 $\left(1561 \mathrm{~cm}^{-1}\right)$. This may be explained as an indirect effect of the difference in co-ordination mode of the phenoxide oxygen of the in $\mathbf{2}$ and 3. In 2, phenoxide ion serves as a bridging ligand. Consequently, the electronic requirement of the copper ions has to be fulfilled more by the other donor atoms (pyrimidine and azomethine nitrogen). Hence the azomethine nitrogen binds more strongly to the copper ions making the $\mathrm{C}=\mathrm{N}$ bond comparatively weaker. On the other hand in $\mathbf{3}$ phenoxide ion shares greater responsibility of donation being non-bridging in nature, leaving the azomethine nitrogen rather weakly bound. Similar effects are observed in case of $v(\mathrm{C}=\mathrm{C})$ for complexes 2 and $\mathbf{3}$.

In complex 2 the nitrate bands are observed at $807 \mathrm{~cm}^{-1}(v 2)$ $1293 \mathrm{~cm}^{-1}$ and $1470 \mathrm{~cm}^{-1}(\mathrm{v} 3)$ indicating that the nitrate bonding mode is bidentate. On the other hand complex 3 the $v 3$ nitrate vibrations are observed at $1304 \mathrm{~cm}^{-1}$ and $1418 \mathrm{~cm}^{-1}$ and the $v 1$ vibration at $841 \mathrm{~cm}^{-1}$. These results signify a monodentate mode of nitrate binding [26].

The $v(\mathrm{C}=\mathrm{C})$ and $v(\mathrm{C}=\mathrm{N})$ peaks for $4,4^{\prime}$-bipy in the complex 3 generally coincide with those of the ligands. An additional peak at $848 \mathrm{~cm}^{-1}$ was obtained for 4,4'-bipy [8].

The electronic solution spectra of the complexes were recorded in DMF solution. Complex 1 shows a $n-\pi^{*}$ band of the pyrimidine ring at $332.5 \mathrm{~nm}$ [27]. A broad band at $434 \mathrm{~nm}$ contains the responses for LMCT charge transfer band for pyrimidine $\rightarrow \mathrm{Cu}$ and $\mathrm{S} \rightarrow \mathrm{Cu}$ [28]. The $\mathrm{n}-\pi^{*}$ transition has the highest molar absorption among these bands $\left(\epsilon=30130 \mathrm{~L}^{-1} \mathrm{~mol} \mathrm{~cm}^{-1}\right)$. The $\mathrm{d}-\mathrm{d}$ transitions occur at much lower energy region and are weak in nature. The broad band at $628 \mathrm{~nm}$ is consistent with the broad structured band for square planar (square pyramidal) complexes of copper [29]. Spectra for complex $\mathbf{2}$ and $\mathbf{3}$ are almost similar to that of complex 1. In complex $2, n-\pi^{*}$ transition is observed at $332 \mathrm{~nm}$, Two very prominent charge transfer bands occur at $383 \mathrm{~nm}$ and $429 \mathrm{~nm}$. The former may be assigned to $\mathrm{N}_{(\mathrm{pym})} \rightarrow \mathrm{Cu}$ and the latter to $\mathrm{O}_{\text {(phenoside) }} \rightarrow \mathrm{Cu}$ charge transfer. Much weaker $\mathrm{d}-\mathrm{d}$ band appears at $675 \mathrm{~nm}$ [30]. The CT band in $\mathbf{3}$ for phenolate $\rightarrow \mathrm{Cu}$ appears at a little higher energy ( $426 \mathrm{~nm}$ ) compared to 2 because of the difference of binding mode of the phenolate group in the two compounds. In compound $\mathbf{3}$ one additional CT band corresponding to
$\mathrm{N}_{\left(4,4^{\prime} \text { 'bipyridine }\right)} \rightarrow \mathrm{Cu}$ LMCT appears at $344 \mathrm{~nm}$. The d-d transition bands occur at a lower energy in $\mathbf{3}$ compared to $\mathbf{2}$ in keeping with the higher distortion of geometry of the copper ion environment. The $\epsilon$ value is also considerably higher in the former. In all three complexes intense $\pi-\pi^{*}$ transition bands for ligands are observed at high energy zones.

\subsection{Redox behavior}

All the complexes show two irreversible cathodic responses at a platinum electrode in DMF solution, with $E_{\mathrm{pc}}$ values (versus SCE) at $-0.42 \mathrm{~V}$ and $-0.72 \mathrm{~V}$ for complex $3,0.44 \mathrm{~V}$ and $-0.62 \mathrm{~V}$ volt for complex 2, where as the two reductive responses for complex 1 occurs at $-0.23 \mathrm{~V}$ and $-0.92 \mathrm{~V}$. The two reductive responses may be assigned to $\mathrm{Cu}^{\mathrm{II}} \mathrm{Cu}^{\mathrm{II}} \rightarrow \mathrm{Cu}^{\mathrm{II}} \mathrm{Cu}^{\mathrm{I}}$. and $\mathrm{Cu}^{\mathrm{II}} \mathrm{Cu}^{\mathrm{I}} \rightarrow \mathrm{Cu}^{\mathrm{I}} \mathrm{Cu}^{\mathrm{I}}[4 \mathrm{e}]$ reductions. Both reductions are one electron process compared to $\mathrm{Fe} / \mathrm{Fe}^{+}$process. The difference of the peak positions for the two reductive responses is indicative of the stability of the electro generated $\mathrm{Cu}^{\mathrm{II}} \mathrm{Cu}^{\mathrm{I}}$ mixed valence state [30]. In complex $\mathbf{1}$ if is found to be maximum. The thiolate bridging donor may have also played a role. However the irreversible nature of the reductions point to the non-supportive nature of the ligand systems towards the structural reorientations required for different preferred co-ordination polyhedra for $\mathrm{Cu}(\mathrm{II})$ and $\mathrm{Cu}(\mathrm{I})$.

On an anodic scan between 0 and $1.0 \mathrm{~V}$ the complexes show one oxidative response for $\mathrm{Cu}^{\mathrm{II}} \rightarrow \mathrm{Cu}^{\mathrm{III}}$ between 0.40 and $0.53 \mathrm{~V}$. The peak to peak separation values range between 0.129 and $0.302 \mathrm{~V}$ indicating the irreversible nature of the oxidation. Here again the thiolate-bridged complex undergoes oxidation at the least positive potential. Interestingly, despite the presence of a mononuclear asymmetric unit along with thiolate-bridged dimer, complex 1 shows no additional peak in cathodic as well as anodic scan.

\subsection{Description of the structure}

\subsubsection{Structure of $\left[\mathrm{Cu}_{2}\left(\mathrm{~L}_{1}\right)_{2}\left(\mathrm{NO}_{3}\right)_{2}\right]\left[\mathrm{Cu}\left(\mathrm{L}_{1}\right)\left(\mathrm{NO}_{3}\right)\right]$ (1)}

The crystal structure of $\mathbf{1}$ consists of two crystallographically independent molecules in the asymmetric unit of the complex. One is a binuclear thiolate-bridged pentacoordinated copper(II) complex while the other is its tetracoordinated mononuclear counter part. In the mononuclear unit the ligand acts as a tridentate mono negative NNS donor, using a pyrimidine nitrogen (N10), the azomethine nitrogen (N9) and the thiolato sulphur (S3) atoms. The fourth co-ordination position in the approximately square planar environment of $\mathrm{Cu}$ is occupied by the nitrato oxygen atom. The ligand forms two five membered chelate rings at the copper center. The thiol form of the co-ordinated ligand in the complex is evident from the increased $\mathrm{C} 13-\mathrm{S} 3$ bond length $(1.736 \AA)$ and decreased C13-N8 bond length ( $1.334 \AA$ ) compared to standard bond lengths observed in thione form of other thiosemicarbazone ligands [31]. The deviation of the copper atom from the mean square plane containing S3N904N10 is negligible. The two chelate rings formed by the ligand are strikingly co-planar with a dihedral angle of less than $1^{\circ}$ between the mean planes of Cu2S3C13N8N9 and Cu2N10C15C14N9. This co-planarity of the chelate rings facilitates electron delocalization in the co-ordination sphere rendering enhanced stability to the complex. The thiosemicarbazone bite angles S3Cu2N9 and N10Cu2N9 are observed to be $84.16^{\circ}$ and $81.09^{\circ}$ respectively while the angular measurements of the trans donor ligands, $04 \mathrm{Cu} 2 \mathrm{~N} 9$ and $\mathrm{S} 3 \mathrm{Cu} 2 \mathrm{~N} 10$ are $176.29^{\circ}$ and $165.25^{\circ}$, respectively, showing considerable distortion from ideal square planer angles $\left(90^{\circ}\right.$ and $\left.180^{\circ}\right)$. However the results are in agreement with those reported for similar mononuclear thiosemicarbazone complexes of copper[32]. The deviation of the copper atom from the basal plane is found to be negligible. 
The binuclear unit may simply be regarded as a centrosymmetric dimer of the mononuclear unit, where the two monomeric units are linked by a four membered ring that includes both symmetry related copper atoms and co-ordinated sulphur donors. The local co-ordination environment of each copper comprises of a square pyramidal $\mathrm{N}_{2} \mathrm{OS}_{2}$ chromophore. The geometry around the copper atoms may be described as distorted square pyramidal. Where the basal plane is occupied by a pyrimidine nitrogen (N4), azomethine nitrogen $\mathrm{N}(3)$, a bridging thiolato sulphur (S1) from a mononegative ligand and an oxygen (O1) from a nitrate anion. The apical position is occupied by a bridging thiolate (S1) from another ligand. The bonds formed by the basal ligand atoms with each copper i.e. $\mathrm{Cu}(1)-\mathrm{S}(1), \mathrm{Cu}(1)-\mathrm{N}(3)$ and $\mathrm{Cu}(1)-\mathrm{N}(4)$ are comparable to those observed in the monomeric unit as well as other structurally characterized binuclear thiolato bridged copper complexes [33]. Despite the fact that the co-ordination angles subtended at each copper center is considerably deviated from ideal square planer angles $\left[180^{\circ}\right.$ and $90^{\circ}$ ] (Table S1, Supplementary data), an approximate square pyramidal geometry is established by the calculation of Addison parameter $\tau, \tau=(\beta-\alpha) / 60^{\circ}$. In this case $\alpha$ and $\beta$ are $01 \mathrm{Cu} 1 \mathrm{~N} 3$ and N4Cu1S1 angles respectively giving a $\tau$ value 0.198 [34]. The apical bridging $\mathrm{Cu}-\mathrm{S}$ bonds are comparatively longer than the basal $\mathrm{Cu}-\mathrm{S}$ bonds ( $2.82 \AA$ A versus $2.29 \AA$ ). The dominant Jahn-Teller distortion characteristics to square pyramidal copper complexes seem to be the reason behind it. The opposite interior angles of the $\mathrm{Cu}_{2} \mathrm{~S}_{2}$ tetragonal core are $86.54^{\circ}$ and $93.46^{\circ}$. Thus from the non-equivalence of bond lengths and bond angles it is clear that this is an asymmetric binuclear thiolate double bridged structure. The distance between the two copper atoms is $3.52 \AA$, comparable to other similar complexes. The $\mathrm{Cu}_{2} \mathrm{~S}_{2}$ core is essentially planer, with all the four atoms sitting in the mean plane. This facilitates the magnetic exchange interaction between the Copper atoms. The mean basal planes at each copper atom through Sl01N3N4 show that there is very little deviation $(<0.1 \AA)$ of the atoms from the mean plane. The copper atom is deviated only ca. $0.06 \AA$ towards the apical bridging Sulphur atom. The basal planes of the square pyramid are almost orthogonal with the mean plane of $\mathrm{Cu}_{2} \mathrm{~S}_{2}$ bridge bearing a dihedral angle of $85.9^{\circ}$ in each case.

The binding mode of the $\mathrm{NO}_{3}{ }^{-}$as the fifth coordinating ligand is worth discussing as nitrate ions are reported to bind metals in monodentate, bidentate and anisobidentate fashion [35]. Based on the available parameters for assigning the nitrate-binding mode [36], it was determined that in both the asymmetric units monodentate fashion of nitrate binding is present. It is found that the nitrate ion is almost planer in the crystal.

A closer look at the crystal lattice shows that the two asymmetric units are networked by profound $\mathrm{H}$-bonding interaction. Each binuclear unit is H-bonded to four mononuclear units. In this case the interaction is between a nitrate oxygen and the Hydrogen of the secondary amine group of the $\mathrm{N}(4)$-substituted thiosemicarbazone.

\subsubsection{Structure of the $\left[\mathrm{Cu}_{2}\left(\mathrm{~L}_{2}\right)_{2}\left(\mathrm{NO}_{3}\right)_{2}\right]$ (2)}

This dimeric molecule sits on a crystallographically imposed center of inversion forming a bridged dinuclear structure with each copper being five-coordinate. The geometry around each copper may again be described as an approximate square pyramidal arrangement. Three positions in the basal plane being occupied by the tridentate ligand, acting as a monoanionic NNO donor and the fourth position being occupied by a co-ordinated nitrate. A bridging $\mathrm{O}$ from the second ligand unit occupies the apical position. The basal mean plane of the square pyramid through the pyrimidine nitrogen (N1), the azomethine nitrogen (N4), the phenoxide (01) and the nitrate oxygen (O2) does not contain any of these atoms (The deviations range between 0.167 and $0.201 \AA$ ). The copper atom is deviated by $0.125 \AA$ A towards the apical bridging oxygen. The chelate rings (one five and another six membered) formed by the ligands at each copper center are at a dihedral angle of $9.2^{\circ}$. The angles produced at the axial phenoxide bridge by the basal donors $\left(\sim 374^{\circ}\right)$ shows considerable pyramidal distortion. Overall it may be inferred that complex 2 suffers less distortion $(\tau=0.157$ ) from square pyramidal geometry towards TBP geometry than complex $\mathbf{1}$ in spite of the fact that angular deviations from ideal square planar angles are more pronounced in $\mathbf{2}$ than $\mathbf{1}$. The $\mathrm{Cu}-\mathrm{O}(1)$ (bridging) bond distance is $2.33 \AA$ whereas the $\mathrm{Cu}-\mathrm{O}(1)$ (basal) is $1.921 \AA$ are unexceptional [37], as are the other bond lengths in the co-ordination sphere of each copper atom (Table S1, Supplementary data). The distance between the two copper atoms is $3.18 \AA$ which is more to the higher end of the range (2.9-3.34) $\AA$ reported for $\mathrm{Cu}-\mathrm{Cu}$ distances in macrocyclic and non-macrocyclic bis( $\mu$-phenoxo) bridged dicopper complexes [38]. In this complex the $\mathrm{Cu}_{2} \mathrm{O}_{2}$ core bears dihedral angle of $88.69^{\circ}$ with the mean basal plane of each square pyramid. The internal angles produced at the $\mathrm{Cu}_{2} \mathrm{O}_{2}$ core $\left(96.57^{\circ}\right.$ and $\left.83.43^{\circ}\right)$ are comparable to those observed in the $\mathrm{Cu}_{2} \mathrm{~S}_{2}$ core of complex $\mathbf{1}$.

Unlike complex 1 the nitrate ion is bound to the copper in an anisobidentate fashion. (See Table S2, Supplementary data) however the large nitrate bite angle $\left(118^{\circ}\right)$ supports the view that the second oxygen (04) of the nitrate should be regarded as a sixth co-ordinating ligand approaching vacant the axial end, rather than both oxygens $(02,04)$ of nitrate occupying a single co-ordination position in the basal plane. The $\mathrm{Cu}-\mathrm{O}(4)$ distance of 2.55 A suggests an weak axial interaction. No appreciable $\mathrm{H}$-bonding interaction is observed of either intra or intermolecular nature. From the $\mathrm{Cg}-\mathrm{Cg}$ distances it is observed that there is notable $\pi-\pi$ interaction between the benzene and pyrimidine ring systems between two separate dimeric molecules. However such interaction if present between aromatic rings belonging to same molecule may be weak in nature.

\subsubsection{Structure of $\left[\mathrm{Cu}_{2}\left(\mu-4,4^{\prime}\right.\right.$ bipy $\left.)\left(\mathrm{L}_{2}\right)_{2}\left(\mathrm{NO}_{3}\right)_{2}\right]$ (3)}

The molecular structure of $\mathbf{3}$ shows two pentacoordinated copper ions bridged by a 4,4'-bipyridyl molecule. The co-ordination environment around each copper may be described as irregular, distorted to an extent of $\sim 50 \%$ ( $\tau=0.496$ ) along the path way from square pyramidal towards trigonal bipyramid. Similar to complex $\mathbf{2}$, the ligand $\left(\mathrm{HL}_{2}\right)$ acts as tridentate mono negative donor. The only difference is that the phenoxide group (01) does not operate as a bridging group, i.e. each phenoxide group donates to a single copper ion. The fourth co-ordination position in the basal plane is occupied by the nitrogen (N5) of the bipyridyl bridging ligand. The axial position is occupied by a nitrate donor. In this complex the nitrate acts as a monodentate donor through (O2), the other oxygen (03) is too far away from the copper ion (3.25 $\AA$ ) for any appreciable bonding interaction. The $\mathrm{Cu}-\mathrm{O}(2)$ bonds being the axial one, are found to be the longest (2.247 $\AA$ ) among all five bond lengths in the co-ordination sphere of each copper (Other bond lengths are in the range 1.89-2.03 $\AA$ ). The chelate rings formed by the ligand at each copper center are co-planar, bearing a dihedral angle of only $2.09^{\circ}$. This observation is in contrast to complex $\mathbf{2}$ where a puckering of the chelate rings was observed to accommodate the rigid bis( $\mu$-phenoxo) bridged structure. The two rings of the 4,4'-bipyridyl bridging donor are co-planar to one another in conformation. Hence the compound bears two fold axis of symmetry perpendicular to the plane containing the bipyridyl rings and also a center of symmetry. The distance between the two copper atoms in $11.14 \AA$ ahich is similar to other bipyridyl bridged binuclear complexes [8-10].

There are two intermolecular H-bonding interactions between the hydrogen of azomethine nitrogen atoms (N3) of a unit with the bonded nitrate oxygen (O2) of another unit. The binuclear complexes thus forms a mixed one dimensional co-ordination polymer 
held by both co-ordinate and H-bonds (Fig. S1 in Supplementary data).

\subsection{Magnetic studies}

\subsubsection{Magnetic study on complexes $\mathbf{1}$ and $\mathbf{2}$}

The magnetic behavior of the compound $\mathbf{1}$ is shown in Fig. 7, as a $\chi_{\mathrm{M}} T$ versus $T$ plot. At room temperature the $\chi_{\mathrm{M}} T$ value is $0.860 \mathrm{~cm}^{3} \mathrm{~K} \mathrm{~mol}^{-1}$ which is close to the expected value for two uncoupled copper (II) ions with $g=2.14$. $\chi_{M} T$ increases slightly with lowering of temperature and reaches a maximum of $0.962 \mathrm{~cm}^{3} \mathrm{~K} \mathrm{~mol}^{-1} \mathrm{ca} .7 .3 \mathrm{~K}$. Below this temperature $\chi_{\mathrm{M}} T$ decreases to a value of $0.833 \mathrm{~cm}^{3} \mathrm{~K} \mathrm{~mol}^{-1}$ at $2 \mathrm{~K}$. The shape of this curve indicates dominant ferromagnetic coupling which result from the interaction of the copper(II) ions through sulphur atoms (thioalkoxo-bridges). The $\chi_{M} T$ decreasing observed at low-temperature is may be due to the intermolecular antiferromagnetic exchange and/or the presence of the ZFS of the ground state $(S=1)$.

To determine the exchange parameters via sulphur atoms we have used the Bleaney-Bowers expression for an isotropically coupled pair of $S=1 / 2$ ions [39], (Eq. (1)) and a Curie-Weiss correction. The best fit parameters for the reproducing satisfactorily the experimental data, as shown in Fig. 6 , are $J=+7.6 \mathrm{~cm}^{-1}, \theta=-0.78 \mathrm{~K}$ and $g=2.14$ with $R=1 \times 10^{-5}\left(R=\sum_{i}\left(\chi T_{i \text { calc }}-\chi T_{i \exp }\right)^{2} /\left(\chi T_{\text {iexp }}\right)^{2}\right):$

$\chi_{\mathrm{M}}=\frac{N g^{2} \mu_{\mathrm{B}}^{2}}{k_{\mathrm{B}}(T-\theta)} \frac{2 \exp \left(J / k_{\mathrm{B}}\right)}{1+3 \exp \left(J / k_{\mathrm{B}}\right)}$

For compound 2 the global feature of the $\chi_{\mathrm{M}} T$ versus $T$ curve is characteristic of very weak antiferromagnetic interaction in a dinuclear copper(II) complex and/or intermolecular interaction (Fig. 7). The value of $\chi_{\mathrm{M}} T$ at $300 \mathrm{~K}$ is $0.951 \mathrm{~cm}^{3} \mathrm{~mol}^{-1} \mathrm{~K}$ which is as expected for two uncoupled copper(II) ions $\left(0.475 \mathrm{~cm}^{3} \mathrm{~mol}^{-1} \mathrm{~K}\right.$ per one $\mathrm{Cu}^{\mathrm{II}}$ with $\left.g=2.25\right)$. The $\chi_{\mathrm{M}} T$ values are more or less constant at high temperature and then decreases suddenly in the low-temperature region reaching a value of $0.332 \mathrm{~cm}^{3} \mathrm{~mol}^{-1} \mathrm{~K}$ at $2 \mathrm{~K}$.

The interaction through oxygen atoms was determined by the use of the above equation Eq. (1) The best fit parameters from 300 down to $2 \mathrm{~K}$ are found as $J=-1.8 \mathrm{~cm}^{-1}, \theta=-1.5 \mathrm{~K}$ and $g=2.25$ with an error $R=9.8 \times 10^{-6} \quad\left(R=1 \times 10^{-5}\right) \quad\left(R=\sum_{i}\left(\chi T_{i c a l c}-\chi T_{\text {iexp }}\right)^{2} /\right.$ $\left.\left(\chi T_{i \exp }\right)^{2}\right)$.

The field dependence of magnetization $(0-5.0 \mathrm{~T})$ measured at $2 \mathrm{~K}$ for compound 1 is shown in Fig. $6 \mathrm{~b}$, in the form of $M / N \beta$ (per $\mathrm{Cu}_{2}$ unit) versus $\mathrm{H}$. The magnetization reaches a value of $2.11 \mathrm{~N} \beta$

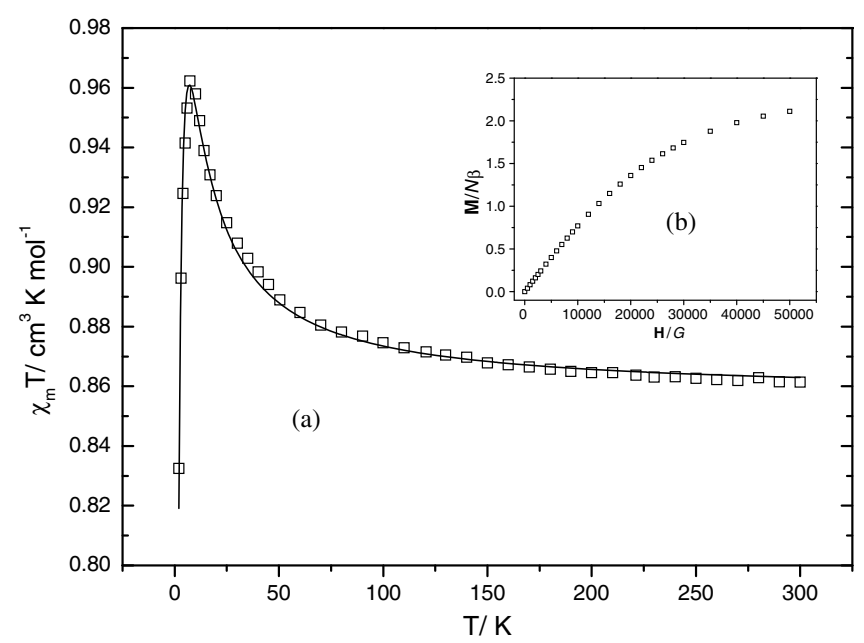

Fig. 6. (a) Plot of the $\chi_{M} T$ vs. $T$ for compound 1. The squares and solid line are the experimental values and the best fit respectively. (b) The field dependence of magnetization at $2 \mathrm{~K}$ for compound $\mathbf{1}$ (per $\left.\mathrm{Cu}_{2}\right)$.



Fig. 7. (a) Plot of the $\chi_{M} T$ vs. $T$ for compound 2. The squares and solid line are the experimental values and the best fit respectively. (b) The field dependence of magnetization at $2 \mathrm{~K}$ for compound 2 .

at 5.0 T which is close to the expected $S=1$ value of $2 \mathrm{~N} \beta$ for the $\mathrm{Cu}_{2}$ system, indicating the presence of ferromagnetic interaction between the nearest copper(II) ions. For compound 2 the field dependence of magnetization $(0-5.0 \mathrm{~T})$ measured at $2 \mathrm{~K}$ is shown in Fig. 7b, reaches a value of $1.7 \mathrm{~N} \beta$ near of two electrons but with a particular shape that we cannot fit satisfactory with Brillouin expression for two isolated ion with $S=1 / 2$. The curves indicate very slow magnetization which is consistent with a net weak antiferromagnetic interaction.

The EPR spectrum of 1 recorded in X band at $4 \mathrm{~K}$ is shown in Fig. S2 (Supplementary data). One band is observed at $g=2.09$ ( $3228.66 \mathrm{G}$ for $v=9.460 \mathrm{GHz}$ ), corresponding to the transition $\Delta M_{\mathrm{S}}= \pm 1$. For the compound 2 (Fig. S3, Supplementary data), two bands are located at $g_{\|}=2.28$ and $g_{\perp}=2.09$ (2962.77 and $3224.75 \mathrm{G}$ for $v=9.458 \mathrm{GHz}$ ).

In order to evaluate the nature of the interaction with similar topology, via sulphur (thioalkoxo-bridges) and oxygen atoms (alkoxo-bridges) in $\mathbf{1}$ and $\mathbf{2}$, respectively, the experimental atomic co-ordinates were performed to obtain the $J$ values. The calculated $J=+9.9 \mathrm{~cm}^{-1}$ for compound $\mathbf{1}$ are reasonably close to the fit value $+7.6 \mathrm{~cm}^{-1}$ but for 2 the calculated $J$ value is $+1.2 \mathrm{~cm}^{-1}$ which contradicts the experimental one $\left(-1.8 \mathrm{~cm}^{-1}\right)$.

To clarify this discrepancy, we have modelled the structure of both compounds attempting to understand the influence of the distance, $d(\mathrm{Cu}-\mathrm{X})$, in the exchange coupling parameter $J$ between nearest copper(II) (Fig. 8). Therefore, in the model 1 we have varied the $\mathrm{Cu}-\mathrm{S}$ distance in the range $2.5-2.9 \AA$ in compound $\mathbf{1}$. In the model 2 , we have varied the $\mathrm{Cu}-\mathrm{O}$ distance in the range 2.1$2.5 \AA$ in compound 2 . The results of these calculations are reported in Fig. 9 as a $J$ versus $d(\mathrm{Cu}-\mathrm{X})$ plots. In the two cases the calculated interactions are ferromagnetic: (i) In the model 1 , the calculated $J$ values are varying between +8.0 and $+27.6 \mathrm{~cm}^{-1}$ showing a clear parabolic dependence with the $\mathrm{Cu}-\mathrm{X}$ distance. (ii) A similar trend was observed in the model 2 , but with small $\mathrm{J}$ values which are varying in the range $\left[+0.3\right.$ to $\left.+4.3 \mathrm{~cm}^{-1}\right]$.

In previous paper, one of us has analyzed the magnetic properties of alkoxo-bridged dinuclear $\mathrm{Cu}(\mathrm{II})$ complexes showing a similar topology of compound 2. The calculated interactions were also weak and ferromagnetic [40]. In the same way, the calculations of model 2 seem to confirm the weak nature of the interaction. The 


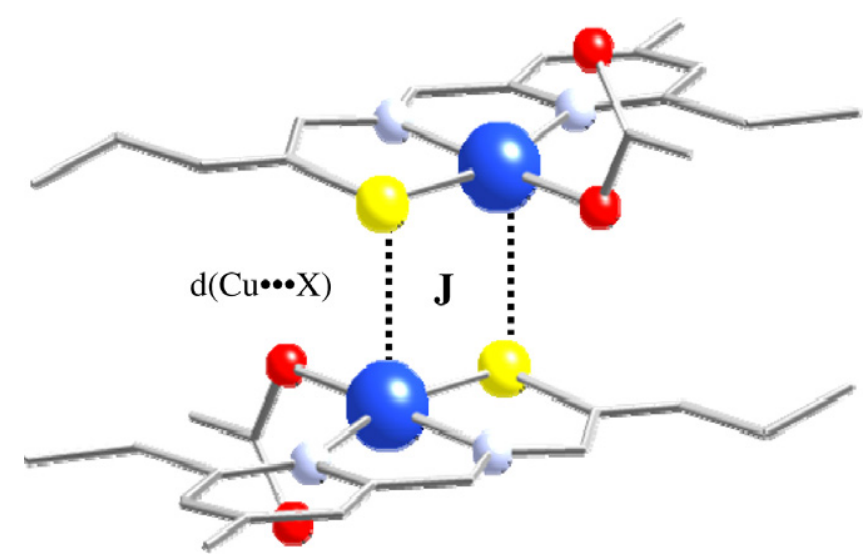

Fig. 8. Molecular structure representation and exchange coupling constant view of compound $\mathbf{1}$. The hydrogen atoms are omitted and the non-environment atoms of copper are represented as sticks for clarity. The dotted line represents the apical distance $\mathrm{Cu}-\mathrm{X}$ that we have varied in mode $\mathrm{l}$ for compound $\mathbf{1}$ and model for compound 2.

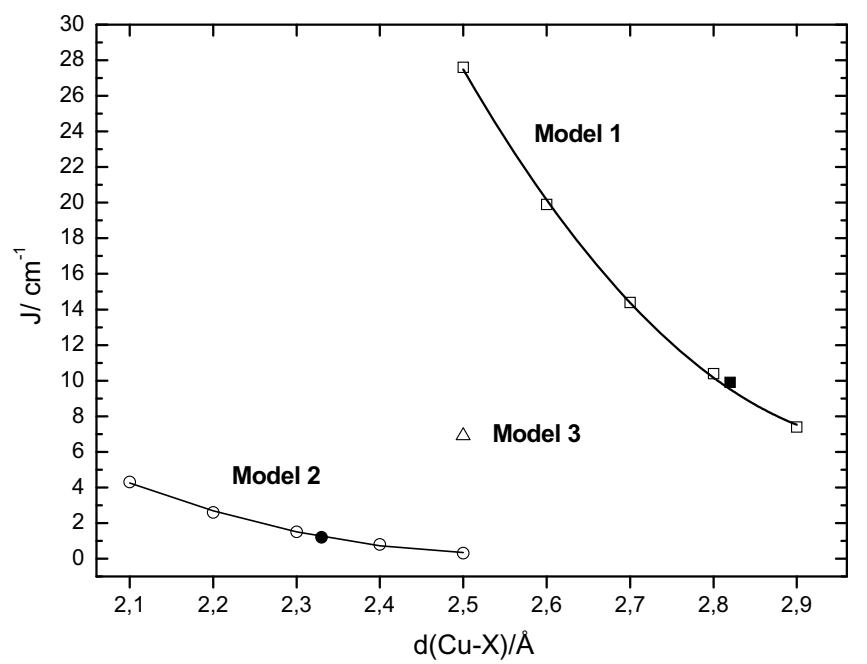

Fig. 9. Variation of the calculated coupling constant as a function of longer distance $\mathrm{Cu}-\mathrm{X}$, for $\mathbf{1}$ (mode1, $\square$ ) and $\mathbf{2}$ (model 2, $\bigcirc$ ). Solids squares and circles represent compound $\mathbf{1}$ and $\mathbf{2}$, respectively. For model $3(\triangle)$ see text.

magnetic behavior can easily be rationalized using the HayThibeault-Hoffmann model [41]. If the coupling constant is given by,

$J=2 K_{a b}-\frac{\left(\varepsilon_{1}-\varepsilon_{2}\right)^{2}}{J_{a a}-J_{a b}}$

the second term will probably be much smaller, result of the poor overlap between the parallel orbitals on the bridge (Fig. S4, Supplementary data). In such situation, the first term, $2 K_{a b}$, is dominating, and leads an overall positive value for the coupling exchange as it shown in compound $\mathbf{1}$. In compound $\mathbf{2}$ this two terms seem to have similar and small values giving a very weak net interaction ferro or antiferromagnetic.

Finally we have substituted in model 1 the sulphur atoms in the bridge by oxygen atoms (with $\mathrm{Cu}-\mathrm{O}$ distance $=2.5 \AA$ ), obtaining a model with a similar bridge of $\mathbf{2}$ (model 3 ) but topologically is close to compound 1 . The calculated $J$ value is $+6.9 \mathrm{~cm}^{-1}$, which is large than the calculated for compound $\mathbf{2}$ by the model 2 (Fig. 9). This agrees with the great ferromagnetic $J$ value calculated for compound 1 by model 1 , indicating the domain of the $2 K_{a b}$ term.

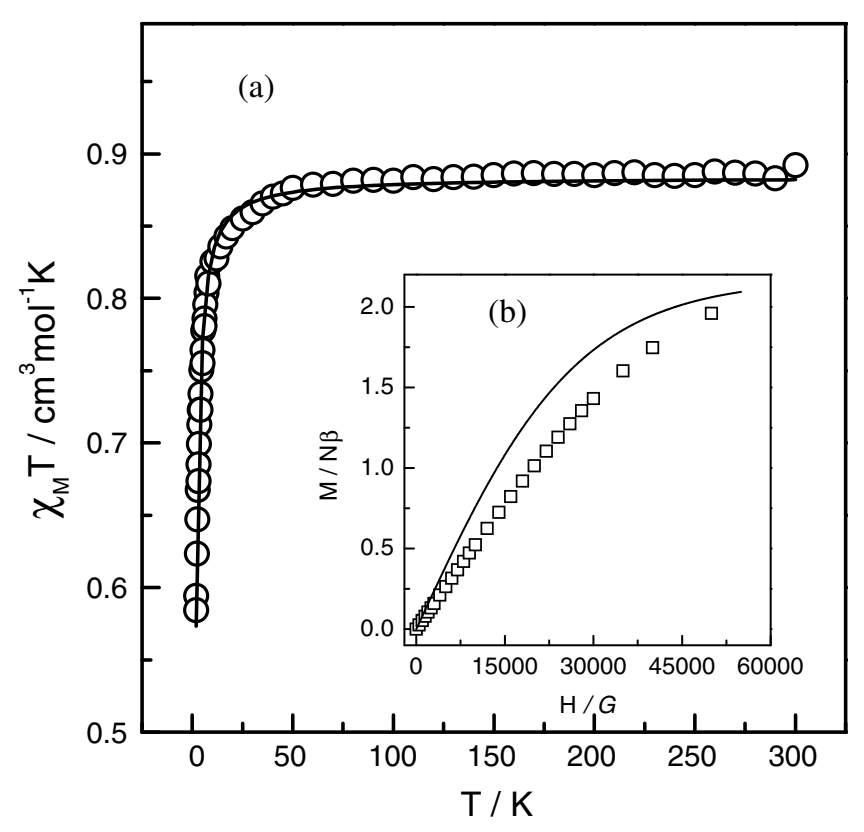

Fig. 10. (a) Plot of the $\chi_{\mathrm{M}} T$ vs. $T$ for compound 3. The squares and solid line are the experimental values and the best fit respectively. (b) The field dependence of magnetization at $2 \mathrm{~K}$ for compound $3\left(\right.$ per $\left.\mathrm{Cu}_{2}\right)$.

\subsubsection{Magnetic study on complex 3}

The magnetic properties of a powder sample of complex $\mathbf{3}$ are represented as $\chi_{\mathrm{M}} T$ versus $T$ in Fig. 10a. At room temperature, the $\chi_{\mathrm{M}} T$ value of the presented complex is $0.883 \mathrm{~cm}^{3} \mathrm{~mol}^{-1} \mathrm{~K}$. This value correspond to two isolated copper(II) ions with one unpaired electron with $g=2.17$. With decreasing temperature, the $\chi_{M} T$ value remains almost constant until ca. $25 \mathrm{~K}$ and then it decreases sharply, giving the minimum value of $0.594 \mathrm{~cm}^{3} \mathrm{~K} \mathrm{~mol}^{-1}$ at $2 \mathrm{~K}$. The drop in $\chi_{\mathrm{M}} T$ at low-temperatures indicates the presence of a very weak antiferromagnetic coupling between the copper(II) ions.

Analysis of the experimental magnetic data was performed by using the Bleaney-Bowers expression, based on the following isotropic Hamiltonian: $H=-J\left(S_{1} \cdot S_{2}\right)$ :

$\chi_{\mathrm{M}}=\frac{N g^{2} \mu_{\mathrm{B}}^{2}}{k T} \frac{2 \exp (J / k T)}{1+3 \exp (J / k T)}$

The parameters $N, \mu_{\mathrm{B}}$ and $k$ in Eq. (2) have their usual meanings, $J=$ Singlet-triplet splitting. Least-square fitting of experimental data leads to the following parameter $J=-1.6 \mathrm{~cm}^{-1}$ and $g=2.17$.indicating a very weak coupling, as may be expected from the 4,4'-bipyridyl bridge. This weak magnetic exchange can be understood considering the large $\mathrm{Cu}$...Cu distance (11.15 $\mathrm{A})$.

The very weak antiferromagnetic interaction was confirmed by magnetization measurements at $2 \mathrm{~K}$ up to an external field of 5.5 T. At higher field, the magnetization in $\mathrm{M} / \mathrm{N} \beta$ units indicates a two isolated quasi-saturated $S=1 / 2$ system for the compound (Fig. $10 \mathrm{~b})$. Comparison of the overall shape of the plot with the Brillouin plot for a fully two isolated ion with $S=1 / 2$ system indicates very slower magnetization which consistent with a weak antiferromagnetic interaction.

The EPR of spectra complex 3 at low-temperatures maintain the same shapes and $g$ values as the EPR spectrum at room temperature. The EPR spectrum of the studied compound shows three signals that are quite close and partially overlapped, (see Fig. S5, Supplementary data). The spectrum is a typical rhombic one with three $g$ values at $g_{1}=2.24, g_{2}=2.09$ and $g_{3}=2.027$ for the compound. It is necessary to highlight that the foregone signal of $D M s= \pm 2$ for a triplet which should appear in the range 1500 $1600 \mathrm{G}$ have not been observed for the complexes 1, 2 and 3. 
The weak exchange pathways parameter, $J$; observed in $\mathbf{3}$ was confirmed by the density functional calculations where the experimental atomic co-ordinates of the compound were performed to obtain the $J$ value, giving $-0.3 \mathrm{~cm}^{-1}$. In this compound the spin distribution is mainly localized in $\mathrm{d}\left(x^{2}-y^{2}\right)$ orbital as we can observe in the Fig. S6 (Supplementary data) due to the large separation between the $\mathrm{Cu}(\mathrm{II})$ paramagnetic centers.

\subsection{Computational details}

The followed computational strategy to calculate the exchange coupling constants in transition metal complexes was described in previous papers [42-44]. The exchange coupling constants are introduced by a phenomenological Heisenberg Hamiltonian $H=-\sum J S_{i} \cdot S_{j}$ (where $i$ and $j$ make reference to the different paramagnetic centers) to describe the interactions between the two paramagnetic transition metals present in the dinuclear complex.

The hybrid B3LYP functional [45] has been used in all calculations as implemented in GAUSSIAN-03 [46] mixing the exact Hartree-Fock-type exchange with Becke's expression for the exchange functional [47] and that proposed by Lee-Yang-Parr for the correlation contribution [48]. Such functional provides calculated $J$ values in excellent agreement with the experimental values $[42,49,50]$. Basis sets proposed by Schaefer et al. have been employed throughout, triple- $\zeta$ quality for the copper atoms [51] and double- $\zeta$ for main group elements [52].

\section{Conclusion}

On a final note, a study on the difference in magnetic behavior of the complexes $\mathbf{1}$ and $\mathbf{2}$ has revealed that the major factor in controlling the magnetic interaction between the $\mathrm{Cu}$ atoms is the overlap between the parallel orbitals on the bridge. Both the bridging donor atom and the ligand topology are contributory factors for an effective overlap. Further, molecular modelling studies between these two complexes have led to a conclusion that the ligand topology factor dominates the bridging donor atom factor. From a synthetic point of view, ligand $\mathrm{HL}_{2}$ demonstrates two possible binding modes in complex 2 and 3. Such versatility in its binding modes has been instrumental in the $\mathrm{pH}$ dependant conversion of $\mathbf{3}$ into 2. Both the complexes are weakly antiferromagnetic but have slightly different magnetic properties. This phenomenon opens the door towards the potential use of similar ligand systems of multi-utility for the design of metal complexes with magnetic properties tuneable with change of $\mathrm{pH}$ of the medium.

\section{Acknowledgements}

Acknowledgement is made to the University Grants Commission, New Delhi, India, for awarding a major research project in science [F.30-65/2004(SR)] to S.K. Kar, M. Salah El Fallah and JavierTercero acknowledges the support through grants given by The financial support given by the Spanish (CTQ2006-01759, CTQ2005-08123-C02-02/BQU) and Catalan (2005SGR-00593, 2005SGR-00036) governments. J. Tercero is grateful to the Centre de Computació de Catalunya (CESCA) with a grant provided by Fundació Catalana per a la Recerca (FCR) and the Universitat de Barcelona.

\section{Appendix A. Supplementary data}

CCDC 674803, 674804 and 674805 contain the supplementary crystallographic data for the complexes 1, 2 and 3. These data can be obtained free of charge via http://www.ccdc.cam.ac.uk/con- ts/retrieving.html, or from the Cambridge Crystallographic Data Centre, 12 Union Road, Cambridge CB2 1EZ, UK; fax: (+44) 1223336-033; or e-mail: deposit@ccdc.cam.ac.uk. Other supplementary materials contain epr spectral diagrams at $4 \mathrm{~K}$ for complexes 1, 2, 3 (Figs. S2, S3, S5), H-bonding mode of complex 3 (Fig. S1), Spin density maps of complexes 1 and $\mathbf{3}$ (Figs. S4 and S6), table for bond distances of complexes 1, 2, $\mathbf{3}$ (Table S1) and another table containing parameters for assigning the nitrate binding mode of complex $\mathbf{1}, \mathbf{2}$, 3 (Table S2). Supplementary data associated with this article can be found, in the online version, at doi:10.1016/j.poly.2008.05.009.

\section{References}

[1] (a) K.D.Karlin, Karlin, Z.Tyeklàr, Tyeklàr, Bioinorganic Chemistry of Copper, Chapman \& Hall, New York, 1993;

(b) K.D.Karlin, Karlin, Z.Tyeklàr, Tyeklàr, A.D. Zuberbühler, in: J. Reedijk (Ed.), Bioinorganic Catalysis, Marcel Dekker, New York, 1993, p. 261;

(c) K.D. Karlin, S. Kaderli, A.D. Zuberbühler, Acc. Chem. Res. 30 (1997) 139;

(d) K.D. Karlin, S. Kaderli, A.D. Zuberbühler, W.B. Tolman, Acc. Chem. Res. 30 (1997) 327

[2] (a) K.D. Karlin, Y. Gultneh, Prog. Inorg. Chem. 35 (1987) 219;

(b) Z. Tyeklàr, K.D. Karlin, Acc. Chem. Res. 22 (1989) 241;

(c) K.D. Karlin, Z. Tyeklàr, Adv. Inorg. Biochem. 9 (1993) 123;

(d) T.N. Sorrell, Tetrahedron 45 (1989) 3;

(e) P.A. Vigato, S. Tamburini, D.E. Fenton, Coord. Chem. Rev. 106 (1990) 25.

[3] (a) (a) N. Kitajima, Adv. Inorg. Chem. 39 (1992) 1;

(b) N. Kitajima, Y. Moro-oka, Chem. Rev. 94 (1994) 737;

(c) L.I. Simàndi, Catalytic Activation of Dioxygen by Metal Complexes, Kluwer, Dordrecht, 1992 (Chapter 5);

(d) E. Spodine, J. Manzur, Coord. Chem. Rev. 119 (1991) 171;

(e) S. Mahapatra, J. Halfen, A.E.C. Wilkinson, G. Pan, C.J. Cramer, L Que.L.Q. Jun, W.B. Tolman, J. Am. Chem. Soc. 117 (1995) 8865.

[4] (a) E.I. Solomon, M.J. Baldwin, M.D. Lowery, Chem. Rev. 92 (1992) 521;

(b) E.I. Solomon, in: T.G. Spiro (Ed.), Copper Proteins, Wiley, New York, 1981.

(Chapter 2);

(c) K. Lerch, Life Chem. Rep. 5 (1987) 221;

(d) D.A. Robb, in: R. Lontie (Ed.), Copper Proteins and Copper Enzymes, vol. 2, CRC Press, Boca Raton, FL, 1984;

(e) R. Gupta, S. Mukherjee, R. Mukherjee, J. Chem. Soc., Dalton Trans. (1999) 4025 .

[5] C.A. Reed, R.D. Orosz, Spin Coupling Concepts in Bioinorganic Chemistry, in: C.J. O'Connor (Ed.), World Scientific, Singapore, 1993, p. 351.

[6] (a) K.A. Magnus, H. Ton-That, J.E. Carpenter, Chem. Rev. 94 (1994) 727; (b) E.I. Solomon, U.M. Sundaram, T.E. Machonkin, Chem. Rev. 96 (1996) 2563.

[7] F. Zippel, F. Ahlers, R. Werner, W. Haase, H.-F. Noltine, B. Krebs, Inorg. Chem. 35 (1996) 3409.

[8] A.J. Blake, S.J. Hill, P. Hubberstey, W-S. Li, J. Chem. Soc., Dalton Trans. (1998) 909.

[9] S.K. Ghosh, J. Ribas, P.K. Bharadwaj, Cryst. Eng. Commun. 6 (45) (2004) 250.

[10] R.l. Baldoma, M. Monfort, J. Ribas, X. Solans, M.A. Maestro, Inorg. Chem. 45 (2006) 8144

[11] (a) R.B. Robson, F. Abrahams, S.R. Batten, R.W. Gable, B.B.F. Hoskins, J. Liu, Supramolecular Architecture, ACS, Washington, DC, 1992. (Chapter 19); (b) M.Y. Fujita, J. Kwon, S. Washizu, S.K. Ogura, J. Am. Chem. Soc. 116 (1994) 1151;

(c) G.R. Desiraju, Crystal Engineering: The Design of Organic Solids, Elsevier, Amsterdam, 1989;

(d) G.R. Desiraju, Angew. Chem. 107 (1995) 2541;

(e) G.R. Desiraju, Angew. Chem., Int. Ed. Engl. 35 (1995) 2311

[12] J.S. Seo, D. Whang, H. Lee, S.I. Jun, J. Oh, Y.J. Jeon, K. Kim, Nature 404 (2000) 982. and references cited therein.

[13] M. Kondo, T. Okubo, A. Asami, S. Noro, T. Yoshimoti, S. Kitagawa, T. Ishii, H. Matsukawa, K. Seki, Angew. Chem., Int. Ed. Engl. 38 (1999) 140. and references cited therein.

[14] (a) E. Coronado, P. Delhaes, D. Gatteschi, J.S. Miller (Eds.), Molecular Magnetism: from Molecular Assemblies to DeVices, NATOASI Series E3211996, Kluwer, Dordrecht, The Netherlands;

(b) J.S. Miller, M. Drillon (Eds.), Magnetism: Molecules to Materials, vols. 152000-2005, Wiley, New York.

[15] (a) J. Garcia-Tojal, M.K.R. Cortes, L. Lezama, M.I. Arriortua, T.J.T. Rojo, J. Chem. Soc., Dalton Trans. (1994) 2233;

(b) P. Gomez-Saiz, J. Garcia-Tojal, A. Mendina, B. Donadieu, L. Lezama, J.L. Pizarro, M.I. Arriortua, Eur. J. Inorg. Chem. (2003) 518.

[16] N. Gupta, S. Mukerjee, S. Mahapatra, M. Ray, R. Mukherjee, Inorg. Chem. 31 (1992) 39.

[17] D. Ghosh, R. Mukherjee, Inorg. Chem. 37 (1998) 6597.

[18] H. Bredereck, R. Sell, F. Effenberger, Chem. Ber. 97 (1964) 3406.

[19] S. Pal, A.K. Barik, P. Aich, S.M. Peng, G.H. Lee, S.K. Kar, Struct. Chem. 18 (2007) 149.

[20] B. Chiswell, F. Lions, Aust. J. Chem. 22 (1961) 71.

[21] G.M. Kosolapoff, C.H. Roy, J. Org. Chem. 26 (1961) 1895. 
[22] M.P.V. Boarland, J.F.W. McOmie, R.N. Timms, J. Chem. Soc. (1952) 4693.

[23] (a) S.C. Ghan, L.L. Koh, P.H. Leung, J.D. Ranford, K.Y. Sim, Inorg. Chim. Acta 23 (1995) 101;

(b) E.W. Ainscough, A.M. Brodie, J.D. Ranford, J.M. Waters, K.S. Murray, Inorg. Chim. Acta 197 (1992) 107.

[24] M. Joseph, V.M. Suni, R.P. Kurup, M. Nethaji, A. Kishore, S.G. Bhat, Polyhedron 23 (2004) 3069.

[25] K. Nakamoto, Infrared and Raman Spectra of Inorganic and Coordination Compounds, 5th ed., Part B, Wiley, New York, p. 88

[26] N.F. Curtis, Y.E.M. Curtis, Inorg. Chem. 4 (1965) 804.

[27] (a) D.X. West, N.M. Kozub, G.A. Bain, Transition Met. Chem. 21 (1996) 52; (b) D.X. West, J.S. Ives, J. Krejct, M.M. Salberg, T.L. Zumbahlen, G.A. Bain, A.E Liberta, J.V. Martinez, S.H. Ortiz, R.A. Toscano, Polyhedron 14 (1995) 2189.

[28] E. Ainscough, A.M. Brodie, N.G. Larsen, Inorg. Chim. Acta 60 (1982) 25.

[29] A.B.P. Lever, Inorganic Electronic Spectroscopy, 2nd ed., Elsevier, Amsterdam, 1984.

[30] S.K. Mandal, L.K. Thompson, K. Nag, J.P. Charland, E.J. Gabe, Inorg. Chem. 26 (1987) 1391.

[31] E. Ainscough, A.M. Bordie, E.N. Bake, R.J. Cresswell, J. Ranford, J.M. Waters, Inorg. Chim. Acta 172 (1990) 185.

[32] V. Philip, V. Suni, M.R.P. Kurup, M. Nethaji, Polyhedron 23 (2004) 1225.

[33] M. Joseph, V. Suni, M.R.P. Kurup, M. Nethaji, A. Kishore, S.G. Bhat, Polyhedron 23 (2004) 3069.

[34] A.W. Addison, T.N. Rao, J. Chem. Soc., Dalton Trans. (1984) 1349.

[35] (a) R. Han, G. Parkin, J. Am. Chem. Soc. 113 (1991) 9707;

(b) C. Kimblin, V.J. Murphy, T. Hascall, B.M. Bridgewater, J.B. Bonanno, G. Parkin, Inorg. Chem. 39 (2000) 967.

[36] G.J. Kleywegt, W.G.R. Wiesmeijer, G.J. Van Driel, W.L. Driessen, J. Reedijk, J.H. Noordik, J. Chem. Soc., Dalton Trans. (1985) 2177.

[37] H. Saimiya, Y. Sunatsuki, M. Kojima, S. Kashino, T. Kambe, M. Hirotsu, H. Akashi, K. Nakajima, T. Tokii, J. Chem. Soc., Dalton Trans. (2002) 3737.

[38] (a) H. Adams, N.A. Bailey, I.K. Campbell, D.E. Fenton, Q.Y. He, J. Chem. Soc., Dalton Trans. (1996) 2233;

(b) D. Black, A.J. Blake, K. Dancey, P. Harrison, A.M. McPartlin, S.P. Parsons, P.A. Tasker, A.G. Whittaker, M. Schröder, J. Chem. Soc., Dalton Trans. (1998) 3953; (c) Y. Sunatsuki, M. Nakamura, N. Matsumoto, F. Kai, Bull. Chem. Soc. Jpn. 70
(1997) 1851;

(d) M. Vaidyanathan, R. Viswanathan, M. Palaniandavar, T. Balasubramanian, P. Prabhakaran, T.P. Muthiah, Inorg. Chem. 37 (1998) 618.

[39] B. Bleaney, K.D. Bowers, Proc. Roy. Soc. London, Ser. A 214 (1952) 451.

[40] J. Tercero, E. Ruiz, S. Alvarez, A. Rodríguez-Fortea, P. Alemany, J. Mater. Chem. 16 (2006) 2729. and references cited therein.

[41] P.J. Hay, J.C. Thibeault, R. Hoffmann, J. Am. Chem. Soc. 97 (1975) 4884.

[42] E. Ruiz, P. Alemany, S. Alvarez, J. Cano, J. Am. Chem. Soc. 119 (1997) 1297.

[43] E. Ruiz, A. Rodríguez-Fortea, J. Cano, S. Alvarez, P. Alemany, J. Comp. Chem. 24 (2003) 982.

[44] E. Ruiz, J. Cano, S. Alvarez, P. Alemany, J. Comp. Chem. 20 (1999) 1391

[45] A.D. Becke, J. Chem. Phys. 98 (1993) 5648.

[46] M.J. Frisch, G.W. Trucks, H.B. Schlegel, G.E. Scuseria, M.A. Robb, J.R. Cheeseman, J.A. Montgomery, T. Vreven, K.N. Kudin, J.C. Burant, J.M. Millam, S.S. Iyengar, J Tomasi, V. Barone, B. Mennucci, M. Cossi, G. Scalmani, N. Rega, G.A. Petersson, H. Nakatsuji, M. Hada, M. Ehara, K. Toyota, R. Fukuda, J. Hasegawa, H. Ishida, T. Nakajima, Y. Honda, O. Kitao, H. Nakai, M. Klene, X. Li, J.E. Knox, H.P. Hratchian, J.B. Cross, C. Adamo, J. Jaramillo, R. Gomperts, R.E. Stratmann, O. Yazyev, A.J. Austin, R. Cammi, C. Pomelli, J. Ochterski, P.Y. Ayala, K. Morokuma, G.A. Voth, P. Salvador, J.J. Dannenberg, V.G. Zakrzewski, S. Dapprich, A.D. Daniels, M.C. Strain, O. Farkas, D.K. Malick, A.D. Rabuck, K. Raghavachari, J.B. Foresman, J.V. Ortiz, Q. Cui, A.G. Baboul, S. Clifford, J. Cioslowski, B.B. Stefanov, G. Liu, A. Liashenko, P. Piskorz, I. Komaromi, R.L. Martin, D.J. Fox, T. Keith, M.A. AlLaham, C.Y. Peng, A. Nanayakkara, M. Challacombe, P.M.W. Gill, B. Johnson, W. Chen, M.W. Wong, C. Gonzalezm, J. A. Pople, Gaussian 03 (Revision B.4), Pittsburgh, PA, 2003.

[47] A.D. Becke, Phys. Rev. A 38 (1988) 3098.

[48] C. Lee, W. Yang, R.G. Parr, Phys. Rev. B 37 (1988) 785.

[49] E. Ruiz, J. Cano, S. Alvarez, P. Alemany, J. Am. Chem. Soc. 120 (1998) 11122.

[50] E. Ruiz, S. Alvarez, A. Rodríguez-Fortea, P. Alemany, Y. Pouillon, C. Massobrio, in: J.S. Miller, M. Drillon (Eds.), Electronic Structure and Magnetic Behavior in Polynuclear Transition-metal Compounds, Wiley-VCH, Weinheim, 2001.

[51] A. Schaefer, C. Huber, R. Ahlrichs, J. Chem. Phys. 100 (1994) 5829.

[52] A. Schaefer, H. Horn, R. Ahlrichs, J. Chem. Phys. 97 (1992) 2571. 